\title{
Comparison of Renal Function and Other Health Outcomes in Vegetarians versus Omnivores in Taiwan
}

\author{
Chih-Kuang Lin ${ }^{1,2,3}$, Deng-Juin Lin ${ }^{1,4}$, Chi-Hwa Yen ${ }^{3,5,6}$, Shiuan-Chih Chen ${ }^{3,5,6}$, Chun-Chieh \\ Chen ${ }^{3,5,6}$, Tsun-Yen Wang ${ }^{4}$, Ming-Chih Chou ${ }^{1,5,6}$, Horng-Rong Chang ${ }^{1,2}$, and Meng-Chih Lee $e^{1,5,6}$ \\ 'Institute of Medicine, Chung Shan Medical University, Taichung 402, Taiwan, ²Division of Nephrology, Department of \\ Internal Medicine, Chung Shan Medical University Hospital, Taichung 402, Taiwan, ${ }^{3}$ School of Medicine, Chung Shan Medical \\ University, Taichung 402, Taiwan, ${ }^{4}$ Bureau of Health, Taichung City, Taiwan, ${ }^{5}$ Center for Education and Research on Geriatrics \\ and Gerontology, Chung Shan Medical University, Taichung 402, Taiwan, and ${ }^{6}$ Department of Family and Community Medicine, \\ Chung Shan Medical University Hospital, Taichung 402, Taiwan
}

\begin{abstract}
Renal disease is one of the top 10 leading causes of death, and the incidence of end-stage renal disease in Taiwan is the highest in the world. Many dietitians consider the diet of plant origin consumed by vegans to be 'lighter' and 'more healthful' than the diet of both plant and animal origin consumed by omnivores. Dietary protein has significant effects on renal functions. The study explored the effects of both the diets on renal functions. The study subjects included 102 Buddhist nun vegetarians and an equal number of matched control group (omnivores). A cross-sectional study was performed to investigate the effects of the diet of plant origin and the diet of both plant and animal origin on renal functions. There was no difference in the renal functions between the two groups. However, systolic blood pressure, blood urea nitrogen, serum sodium, glucose, cholesterol levels, and urinary specific gravity were lower in the vegetarian group. Although these results were compatible with general concepts regarding diet of plant origin, after adjusting for age, the duration of intake of this diet had no effect on the renal functions. Based on the findings, it is concluded that the renal functions, in terms of the estimated glomerular filtration rate, were not different between the vegetarians and the omnivores.
\end{abstract}

Key words: Cross-sectional studies; Diet; Diet, Vegetarian; Renal function; Taiwan

\section{INTRODUCTION}

In the last few years, renal disease has become one of the 10 leading causes of death in Taiwan. Results of an analysis of the United States Renal Data System (USRDS) showed that the incidence rates of reported end-stage renal disease (ESRD) in 2007 were the highest in Taiwan, at 415 per million population, followed by Mexico, the United States, Japan, and Turkey, at 372, 361, 285, and 229 per million population respectively (1). In 2009, the Department of Health, Taiwan, reported that mortality due to nephritis, nephrotic syndrome, and other

Correspondence and reprint requests should be addressed to:

Dr. Meng-Chih Lee or Dr. Horng-Rong Chang Professor, Institute of Medicine

Chung Shan Medical University

110, Section 1 Chien Kuo North Road

Taichung 402

Taiwan

Email: mcl@csmu.edu.tw

Fax: 886-4-23248137 kidney diseases was the 10th leading cause of death in Taiwan (2).

The diet of plant origin has become popular in Taiwan because many perceive it as a 'lighter' alternative and is, therefore, more healthful. Many studies focused on the impact of a diet of plant origin on nutrition and health (3). Hyperlipidaemia, persistent proteinuria, glomerular hyperfiltration, and hypertension may contribute to the deterioration of renal functions. In addition, excess protein may also exacerbate renal functions, especially with diabetic nephropathy. Results of some studies, using animal and human models, suggest that restrictions of dietary protein can significantly retard the progression of chronic renal insufficiency (4-6). Diet of vegetarians rich in plant proteins, especially soy-proteins, has positive effects on blood pressure and lipid profiles. These positive effects include an improvement in proteinuria, hyperfiltration and renal perfusion, and decreased renal injury. To prevent or delay further progression of kidney damage 
in diabetic nephropathy, results of studies suggest replacing animal protein with soy-protein (7-9). However, the impact of diet of the vegetarians on protecting renal function remains unclear. The aim of this study was to explore the effects of diets of the vegetarian and omnivorous consumers on renal functions.

\section{MATERIALS AND METHODS}

\section{Study subjects}

During March 2006-June 2007, we screened chronic diseases in Taichung City in central Taiwan. Initially, we recruited 105 Buddhist nuns, aged 20-78 years, from a temple. Of the 105 nuns, 102 were enrolled with complete data. The average history of practising diet of plant origin by the subjects was 17.8 years. Omnivorous female subjects were selected through a simple random-sampling method. The study used a 1:1 ratio of age, body mass index (BMI), and education level-matched vegetarian to omnivorous female subjects. The final number of the study subjects included 102 vegetarians and 102 omnivores. Subjects diagnosed with chronic renal diseases in both vegetarian and non-vegetarian groups were excluded.

\section{Biochemical analysis}

We collected fasting blood samples for studying both routine biochemical screening of renal disorders and lipid profile. The study used the Olympus AU-2700 (Olympus Japan Co. Ltd., Tokyo, Japan) and the SYSMEX XE-2100 (TOA Medical Electronics, Kobe, Japan) to measure the biochemical components. These measurements included blood urea nitrogen (BUN), serum creatinine, sodium, potassium, chloride, calcium, phosphorus, uric acid, albumin, fasting plasma glucose, triglycerides, and total cholesterol. The Medical Laboratory of the Chung Shan Medical University Hospital analyzed all the samples.

\section{Definition of terms}

We used serum creatinine, age, and gender to calculate the estimated glomerular filtration rate (eGFR) according to the equation of simplified modification of diet in renal disease (MDRD) (10). Table 1 classifies the renal functions into five stages. This aligns with the national DOQI (Disease Outcomes Quality Initiative) standards.

The Bureau of Health standards for Taiwan considers a BMI of $>24$ to be normal and BMI of $<18$ to be abnormal. Systolic blood pressure of $>130 \mathrm{mmHg}$ and/or diastolic blood pressure of $>80 \mathrm{mmHg}$ is defined as high blood pressure. Hyperglycaemia is defined as fasting plasma glucose of $\geq 100 \mathrm{mg} / \mathrm{dL}$ while hypertriglyceridaemia is defined as serum

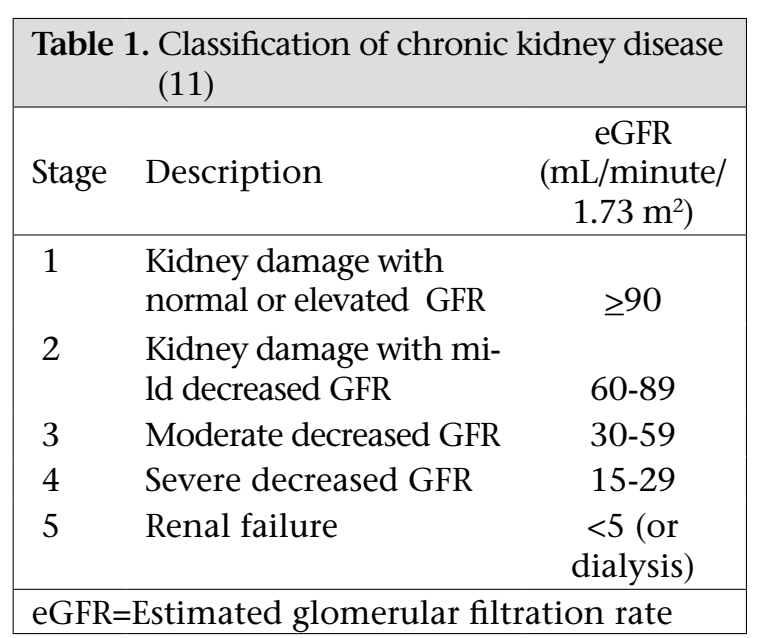

triglycerides of $>150 \mathrm{mg} / \mathrm{dL}$. Hypercholesteraemia is the serum total cholesterol of $>200 \mathrm{mg} / \mathrm{dL}$. Serum creatinine and BUN are elevated if the serum levels are $>1.3 \mathrm{mg} / \mathrm{dL}$ and $>20 \mathrm{mg} / \mathrm{dL}$ respectively. A serum sodium level of $>145 \mathrm{mEq} / \mathrm{L}$ is seen as hypernatraemia. Hyperuricaemia is serum uric acid of $\geq 6 \mathrm{mg} / \mathrm{dL}$. Abnormal urine is an elevated specific gravity ( $\geq 1.020$ ) of urine, proteinuria, haematuria, and pyuria when urine dipstick chemical analysis showed 1+ of protein, occult blood, or leukocyte esterase.

\section{Statistical analysis}

The study used descriptive analysis, $t$-test, regression model, and chi-square analysis. Data were analyzed using the SPSS software (version 12).

\section{RESULTS}

\section{Demographics of vegetarians and omnivores}

Each group had 102 female subjects, and their mean age was 46.6 years (Table 2). Of the subjects, $27.5 \%$, $39.2 \%, 27.5 \%$, and $13.7 \%$ were aged $<39,40-49$, $50-59$, and $>60$ years respectively. Underweight subjects accounted for $2.5 \%$ while $60.8 \%$ were of normal weight, and $36.8 \%$ were overweight. $75.0 \%$ of the subjects had mildly decreased eGFR, $4.9 \%$ moderate decreased eGFR, $0.5 \%$ severe decreased eGFR, $0.5 \%$ end-stage renal failure, and $18.6 \%$ of the subjects had normal eGFR.

\section{Characteristics of omnivores and vegetarians}

Table 3 shows that there was no significant difference in the BMI between the groups. The systolic blood pressure was significantly lower in the vegetarian group compared to the omnivorous group (114.8 \pm 15.7 vs $119.7 \pm 18.5$, $\mathrm{p}=0.04)$, although the diastolic blood pressure of vegetarians was higher compared to the omnivores $(77.0 \pm 10.0$ vs $73.3 \pm 10.1$, $\mathrm{p}=0.01$, indicating a narrow range between systolic blood pressure and diastolic blood pressure in 


\begin{tabular}{|c|c|c|c|c|c|c|}
\hline \multirow{2}{*}{ Characteristics } & \multicolumn{2}{|c|}{ Vegetarians $(\mathrm{n}=102)$} & \multicolumn{2}{|c|}{ Omnivores $(\mathrm{n}=102)$} & \multicolumn{2}{|c|}{ Total } \\
\hline & No. & $\%$ & No. & $\%$ & No. & $\%$ \\
\hline \multicolumn{7}{|l|}{ Age (years)* } \\
\hline$<39$ & 28 & 27.5 & 28 & 27.5 & 56 & 27.5 \\
\hline $40-49$ & 40 & 39.2 & 40 & 39.2 & 80 & 39.2 \\
\hline $50-59$ & 20 & 20.5 & 20 & 20.5 & 40 & 20.5 \\
\hline$>60$ & 14 & 13.7 & 14 & 13.7 & 28 & 8.8 \\
\hline \multicolumn{7}{|l|}{ Educational level* } \\
\hline College and above & 30 & 33.3 & 34 & 29.4 & 64 & 31.4 \\
\hline $\begin{array}{l}\text { Junior and senior high } \\
\text { school }\end{array}$ & 41 & 40.2 & 45 & 44.1 & 86 & 42.1 \\
\hline Primary school & 27 & 26.5 & 27 & 26.5 & 54 & 26.5 \\
\hline \multicolumn{7}{|l|}{ BMI* $^{*}$} \\
\hline$<18$ & 3 & 2.9 & 2 & 2.0 & 5 & 2.5 \\
\hline $18-24$ & 63 & 61.8 & 61 & 59.8 & 124 & 60.8 \\
\hline$>24$ & 36 & 35.3 & 39 & 38.2 & 75 & 36.8 \\
\hline \multicolumn{7}{|l|}{ eGFR $\left(\mathrm{mL} / \text { minute } / 1.73 \mathrm{~m}^{2}\right)^{*}$} \\
\hline$<15$ & 1 & 1.0 & 0 & 0.0 & 1 & 0.5 \\
\hline $15-29$ & 1 & 1.0 & 0 & 0.0 & 1 & 0.5 \\
\hline $30-59$ & 4 & 3.9 & 6 & 5.9 & 10 & 4.9 \\
\hline $60-89$ & 77 & 75.5 & 76 & 74.5 & 153 & 75.0 \\
\hline$>90$ & 19 & 18.6 & 20 & 18.6 & 39 & 18.6 \\
\hline
\end{tabular}

the vegans. The BUN, BUN/creatinine ratio, total cholesterol, and fasting plasma glucose levels were all significantly lower $(\mathrm{p}<0.05)$ in the vegetarian group. However, creatinine, uric acid, and triglyceride levels were not different. The eGFR was 79.6 $\mathrm{mL} / \mathrm{minute} / 1.73 \mathrm{~m}^{2}$ in the vegetarian group and $79.0 \mathrm{~mL} / \mathrm{minute} / 1.73 \mathrm{~m}^{2}$ in the omnivorous group without any significant difference.

\section{Abnormal levels in vegetarian and omnivorous groups}

Table 4 shows that there were no significant differences in the elevated BMI or elevated blood pressure.

The proportion of subjects with hypernatraemia

\begin{tabular}{|c|c|c|c|}
\hline Variable & $\begin{array}{l}\text { Vegetarians } \\
(\mathrm{n}=102) \\
\text { mean } \pm \mathrm{SD}\end{array}$ & $\begin{array}{c}\text { Omnivores } \\
(\mathrm{n}=102) \\
\text { mean } \pm \mathrm{SD}\end{array}$ & $\mathrm{p}$ value \\
\hline Age (years) & $46.6 \pm 11.3$ & $45.5 \pm 13.4$ & 0.50 \\
\hline Body mass index & $23.4 \pm 3.9$ & $23.3 \pm 3.5$ & 0.73 \\
\hline Systolic blood pressure (mmHg) & $114.8 \pm 15.7$ & $119.7 \pm 18.5$ & $0.04^{*}$ \\
\hline Diastolic blood pressure (mmHg) & $77.0 \pm 10.0$ & $73.3 \pm 10.1$ & $0.01^{*}$ \\
\hline BUN (mg/dL) & $10.9 \pm 4.8$ & $13.8 \pm 4.6$ & $<0.001^{*}$ \\
\hline Creatinine (mg/dL) & $0.9 \pm 0.3$ & $0.9 \pm 0.1$ & 0.75 \\
\hline $\mathrm{BUN} /$ creatinine ratio & $12.7 \pm 3.7$ & $16.1 \pm 4.5$ & $<0.001^{*}$ \\
\hline Sodium (mEq/L) & $139.0 \pm 7.4$ & $144.3 \pm 2.3$ & $<0.001^{*}$ \\
\hline Uric acid (mg/dL) & $4.8 \pm 1.0$ & $4.8 \pm 1.2$ & 0.92 \\
\hline Fasting plasma glucose (mg/dL) & $76.6 \pm 28.2$ & $88.6 \pm 21.4$ & $0.001^{*}$ \\
\hline Trigycerides $(\mathrm{mg} / \mathrm{dL})$ & $123.7 \pm 78.5$ & $104.2 \pm 70.4$ & 0.06 \\
\hline Cholesterol (mg/dL) & $168.8 \pm 33.0$ & $186.6 \pm 31.8$ & $<0.001^{*}$ \\
\hline eGFR (mL/minute/1.73 m²) & $79.6 \pm 14.7$ & $79.0 \pm 14.4$ & 0.78 \\
\hline
\end{tabular}




\begin{tabular}{|c|c|c|c|c|c|}
\hline \multirow{2}{*}{ Unusual situation } & \multicolumn{2}{|c|}{ Vegetarians $(\mathrm{n}=102)$} & \multicolumn{2}{|c|}{ Omnivores $(\mathrm{n}=102)$} & \multirow{2}{*}{$\mathrm{p}$ value } \\
\hline & No. & $\%$ & No. & $\%$ & \\
\hline Elevated BMI & 39 & 38.2 & 41 & 40.2 & 0.74 \\
\hline \multicolumn{6}{|l|}{ Elevated blood pressure } \\
\hline $\mathrm{SBP}>140 \mathrm{mmHg}$ & 9 & 8.8 & 15 & 14.7 & 0.19 \\
\hline $\mathrm{DBP}>90 \mathrm{mmHg}$ & 8 & 7.8 & 2 & 2.0 & 0.05 \\
\hline Elevated BUN & 3 & 2.9 & 6 & 5.9 & 0.34 \\
\hline Elevated creatinine & 2 & 2.0 & 1 & 1.0 & 0.56 \\
\hline Hypernatraemia & 0 & 0.0 & 30 & 29.4 & $<0.001^{*}$ \\
\hline Hyperuricaemia & 10 & 9.8 & 12 & 11.8 & 0.65 \\
\hline Hyperglycaemia & 8 & 7.8 & 12 & 11.8 & 0.35 \\
\hline Hypertriglycaeridaemia & 25 & 24.5 & 15 & 14.7 & 0.08 \\
\hline Hypercholesteraemia & 16 & 15.7 & 30 & 29.4 & $0.02^{*}$ \\
\hline eGFR $<90$ & 83 & 81.4 & 82 & 80.4 & 0.86 \\
\hline Elevated urinary specific gravity & 41 & 40.2 & 78 & 76.5 & $<0.001^{*}$ \\
\hline Protaeinuria & 10 & 9.8 & 4 & 3.9 & 0.10 \\
\hline Haematuria & 31 & 30.4 & 27 & 26.5 & 0.54 \\
\hline Pyuria & 13 & 12.7 & 11 & 10.8 & 0.66 \\
\hline Bactaeriuria & 53 & 52.0 & 42 & 41.2 & 0.12 \\
\hline
\end{tabular}

and hypercholesteraemia was significantly $(\mathrm{p}<0.05)$ lower in the vegetarian group. Other biochemical parameters, including hyperuricaemia, hyperglycaemia, hypertriglyceridaemia, and eGFR, did not show any significant differences.

The proportion of subjects with elevated urinary specific gravity was significantly lower in the vegetarian group ( $40.2 \%$ vs $76.5 \%, \mathrm{p}<0.05$ ). However, other parameters, including proteinuria, haematuria, pyuria, and bacteriuria, were not different.

\section{Duration of diet intake by vegetarians and parameters of health}

The results indicated that the diet of vegetarians might have affected some parameters. Table 5 presents the results on analysis of the effects of the duration of diet intake by vegetarians on health parameters. The age of a vegetarian significantly $(\mathrm{p}<0.05)$ correlated with BUN, cholesterol, and eGFR level. Blood pressure was significantly $(\mathrm{p}<0.05)$ associated with creatinine level. In addition, fasting plasma glucose positively correlated with uric acid and triglyceride levels $(p<0.05)$. The duration of diet intake by vegetarians was not associated with any health markers in the study.

\section{DISCUSSION}

A few studies have explored the effects of diets consumed by vegetarians and omnivores on the nutrition status. Results of a study by Ko et al. in
Taiwan showed blood pressure, cholesterol level, and glucose level to be significantly lower in female vegetarians when compared those in female omnivores. However, this was not evident in male subjects (12). The present study also revealed that blood pressure (systolic), cholesterol level, and glucose level were lower in the vegetarian group. The finding was in agreement with that from previous studies $(13,14)$. In addition, BUN and sodium levels were also lower in the vegetarian group. There was no significant difference in BMI and creatinine, which confirms the findings of Chen et al. (15).

Diastolic blood pressure was significantly higher in the vegetarian group that was discordant with the previously-mentioned Ko study that demonstrated significance only in the female group (12). Therefore, more studies are needed to clarify the association between blood pressure level and vegetarian diet.

Another study in Thailand revealed a significantlylower level of BUN, BUN/creatinine ratio, and a lower urinary protein excretion rate in vegetarians (16). Our study has shown similar results. In addition, the eGFR level was not significantly different between the groups. This suggests that a diet of the vegetarians does not have a significant effect on renal functions.

\section{Conclusions}

The results of the present study showed that renal functions were not different between the vegetar- 


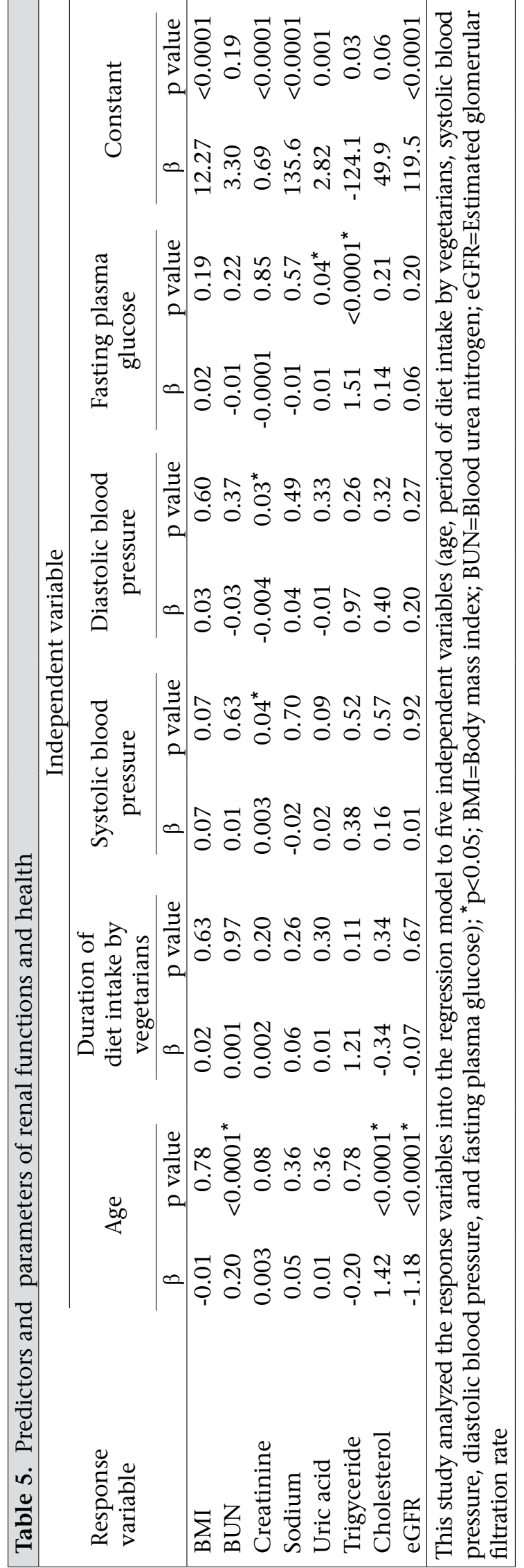

ians and the omnivores. Systolic blood pressure, BUN and sodium, glucose, cholesterol levels, and urinary specific gravity were lower in the vegetarian group. Although these results are compatible with general expectations, after adjusting for age, diet had no effect on renal function. On the other hand, there was a slightly-higher diastolic blood pressure in the vegetarian group. The vegetarians appeared to have lower systolic blood pressure, BUN, BUN/creatinine ratio, sodium, and fasting plasma glucose. Further research should continue to monitor and study the meanings of these parameters.

\section{REFERENCES}

1. United States Renal Data System. International comparisons. In: United States Renal Data System Annual data report. Bethesda, MD: National Institute of Diabetes and Digestive and Kidney Disease, National Institutes of Health, 2009:344-55.

2. Lin MH, Chiang YJ, Li CL, Liu HE. The relationship between optimism and life satisfaction for patients waiting or not waiting for renal transplantation. Transplant Proc 2010;42:763-5.

3. Diet, nutrition, and the prevention of chronic diseases. A report of the WHO study group on diet, nutrition and prevention of noncommunicable diseases. Nutr Rev 1991;49:291-301.

4. Zeller KR. Low-protein diets in renal disease. Diabetes Care 1991;14:856-66.

5. Nakamura H, Takasawa M, Kashara S, Tsuda A, Momotsu T, Ito $\mathrm{S}$ et al. Effects of acute protein loads of different sources on renal function of patients with diabetic nephropathy. Tohoku J Exp Med 1989;159:15362.

6. Kontesis PS, Bossinakou I, Sarika L, Iliopoulou E, Papantoniou A, Trevisan R et al. Renal, metabolic, and hormonal responses to proteins of different origin in normotensive, nonproteinuric type 1 diabetic patients. Diabetes Care 1995;18:1233.

7. Kontessis P, Jones S, Dodds R, Trevisan R, Nosadini $\mathrm{R}$, Fioretto $\mathrm{P}$ et al. Renal, metabolic and hormonal responses to ingestion of animal and vegetable protein. Kidney Int 1990;38:136-44.

8. Anderson JW, Smith BM, Washnock CS. Cardiovascular and renal benefits of dry bean and soybean intake. Am J Clin Nutr 1999;70(Suppl 3):464S-74S.

9. Anderson JW, Bazel GP. Nutritional management of diabetes mellitus. In: Shils MW, Olson JA, Shike M, editors. Modern nutrition in health and disease. $8^{\text {th }}$ ed. Philadelphia: Lea and Febiger, 1994:1259-86.

10. Froissart M, Rossert J, Jacquot C, Paillard M, Houillier P. Predictive performance of the modification 
of diet in renal disease and Cockcroft-Gault equations for estimating renal function. J Am Soc Nephrol 2005;16:763-73.

11. Levey AS, Eckardt KU, Tsukamoto Y, Levin A, Coresh J, Rossert J et al. Definition and classification of chronic kidney disease: a position statement from Kidney Disease: Improving Global Outcomes (KDIGO). Kidney Int 2005;67:2089-100.

12. Ko YC, Chang PY. Effect of aging in vegetarians and non-vegetarians on blood pressure and blood lipids. Nutr Sci J 1983;8:86.
13. Craig WJ. Health effects of vegan diets. Am J Clin Nutr 2009;89:1627S-33S.

14. Hung CJ, Huang PC, Li YH, Lu SC, Ho LT, Chou HF. Taiwanese vegetarians have higher insulin sensitivity than omnivores. Br J Nutr 2006;95:129-35.

15. Chen KJ, Shaw NS, Pan, WH, Lo FL, Lin PF. Effect of a vegetarian diets on the vitamin $\mathrm{B}$ status and homocysteine levels in elderly Taiwanese. Nutr Sci J 2006;31:117-26.

16. Wiwanitkit V. Renal function parameters of Thai vegans compared with non-vegans. Renal Failure 2007;29:219-20. 